\title{
Teratozoospermia: Its association with sperm DNA defects, apoptotic alterations, and oxidative stress
}

\author{
Oumaima Ammar $^{1,2}$ (D) | Meriem Mehdi ${ }^{1,2}$ | Monica Muratori ${ }^{3}$
}

${ }^{1}$ Laboratory of Histology Embryology and Cytogenetics (LR 18 ES 40), Faculty of

Medicine, University of Monastir, Monastir, Tunisia

${ }^{2}$ Laboratory of Cytogenetics and Reproductive Biology, Center of Maternity and Neonatology Monastir, Fattouma Bourguiba University Teaching Hospital, Monastir, Tunisia

${ }^{3}$ Department of Experimental and Clinical Biomedical Sciences "Mario Serio", Unit of Sexual Medicine and Andrology, Center of Excellence DeNothe, University of Florence, Florence, Italy

\section{Correspondence}

Oumaima Ammar, Laboratory of Histology Embryology and Cytogenetics (LR 40 ES 18), Faculty of Medicine, University of Monastir, Avicenne Street, Monastir 5019, Tunisia. Email: ammaroumayma2014@gmail.com

Funding information

This work was supported by funds allocated to the Research laboratory of Histology and Genetic LR40 ES18 by Tunisian Ministry of Higher Education and Scientific Research.

\begin{abstract}
This study was carried out to evaluate the level of nuclear sperm DNA damage in men with isolated polymorphic teratozoospermia and examining its relationship with apoptosis and oxidative stress. A total of 89 subjects were divided into two groups: men with isolated teratozoospermia $(n=69)$ and men with normal semen parameters $(n=20)$ as controls. Sperm DNA breaks were determined by using acridine orange staining. The proportion of viable spermatozoa with mitochondrial transmembrane depolarization was detected by fluorescence microscopy through the use of MitoPTJC-1 staining method. Bivariate Annexin V/6-CFDA analysis was then set out in order to measure the percentage of both viable and dead spermatozoa with phosphatidylserine (PS) externalization. Seminal antioxidant profile (reduced glutathione (GSHr); oxidized glutathione (GSSG); glutathione S-transferase (GST)) and total protein sulfhydryl (P-SH) concentrations were measured spectrophotometrically. Men with isolated teratozoospermia, when compared to controls, showed significantly increased level of single sperm DNA breaks and higher proportions of spermatozoa with phosphatidylserine externalization and mitochondrial depolarization. Among the differently studied oxidative stress seminal parameters, the rates of seminal GSHr, GST, and P-SH were significantly decreased in the teratozoospermic group. However, the seminal rates of GSSG and GST have decreased, but only GST did not show a significant difference. Interestingly, significant correlations were found between the studied apoptotic markers and the rate of atypical sperm forms with the incidences of head abnormalities. Furthermore, positive inter-correlations were found between sperm DNA defects, impaired seminal antioxidant status, and the apoptotic sperm markers. Such data provide clear evidence that the apoptotic alterations are closely correlated to abnormal sperm morphology and DNA damage. Moreover, decreased seminal antioxidant profile may be a crucial factor involved in the mechanism of sperm cell death-mediated DNA breaks in teratozoospermic semen.
\end{abstract}

KEYWORDS

DNA damage, mitochondrial depolarization, phosphatidylserine externalization, seminal antioxidant status, teratozoospermia 


\section{1 | INTRODUCTION}

Over the past years, the cytogenetic investigations of severe teratozoospermia have been one of the most productive areas within the topic of male infertility and assisted conception. ${ }^{1-4}$ Teratozoospermia is defined as a percentage of spermatozoa with normal shape under the lesser reference limit. The cutoff values for normality varied greatly in recent decades from $50 \%$ in the first World Health Organization (WHO) classification ${ }^{5}$ to $4 \%$ according to Kruger classification ${ }^{6}$ or $15 \%$, according to the modified classification of David ${ }^{7}$ in the last published version. ${ }^{5}$ To be treated as morphologically normal, a spermatozoon would have a normal acrosome, an oval head between 2.5 and $3.5 \mu \mathrm{m}$ width and 5 and $6 \mu \mathrm{m}$ long, a midpiece of 4.0 to $5.0 \mu \mathrm{m}$, and a tail about $50 \mu \mathrm{m}$ long. ${ }^{8}$ Several reports have found higher rates of DNA damage, sperm aneuploidy, and protamination defects in infertile men with impaired semen parameters in comparison with controls and their association with morphological abnormalities. ${ }^{2,9-12}$

Not so far, we have found that men with isolated teratozoospermia show numerous nuclear alterations, namely DNA breaks and chromatin decondensation. ${ }^{3,4}$ These results may explain the poor fertility prognosis of these subjects. ${ }^{13-16}$ However, the pathological mechanism linking nuclear defects to abnormal sperm morphology remains unclear.

Three hypotheses have been advanced concerning the origins of DNA damage in the male germ line: (a) the failure of repair of physiological spermatic strand DNA breaks occurring during spermiogenesis as a consequence of activated topoisomerase to relieve the torsional stresses associated with chromatin remodeling, (b) an abortive apoptosis initiated post-meiotically when the ability to drive this process to completion is in decline, ${ }^{17}$ and (c) an oxidative stress (OS). ${ }^{13,18,19}$ Oxidative stress is due to an imbalance between reactive oxygen species (ROS) overproduction and antioxidant scavenging activities in semen. ROS are highly toxic when reacting with nuclear spermatozoa as they originate oxidative base modifications and high levels of DNA Breaks. ${ }^{20,21}$ Interestingly, recent studies have clearly shown that high seminal levels of both lipid peroxidation (LPO) and ROS with decreased antioxidant enzymes were strongly correlated with increased spermatozoa DNA fragmentation and sperm chromatin decondensation in men with isolated teratozoospermia. ${ }^{3,11,22-24}$

On the other hand, many data indicate that poor sperm morphology is associated with higher rates of caspases' expression, ${ }^{24,25}$ suggesting an association between teratozoospermia and apoptosis. Many reports have indicated the occurrence of apoptosis-like characteristics, including DNA breakage, presence of activated caspases, and externalization of the phosphatidylserine (PS) on the sperm plasma membrane in ejaculated human spermatozoa of infertile men with different potential of infertility, ${ }^{12,26-28}$ however, the link between apoptosis and teratozoospermia has been poorly investigated so far.

Therefore, this study aimed to examine the relationship between DNA damage, OS, and apoptosis, the latter investigated by two apoptotic biochemical markers: membrane phosphatidylserine externalization (PS) and mitochondrial function in ejaculated spermatozoa from men with isolated teratozoospermia.

\section{2 | MATERIALS AND METHODS}

\section{1 | Subjects and samples}

The protocol was approved by the local ethics committees, and written informed consent was previously obtained from all studied subjects. This prospective controlled study has involved 69 infertile men referring to consulting clinic of infertility at the Department of Cytogenetic and Reproductive Biology, Fattouma Bourguiba University Teaching Hospital, Monastir, Tunisia. These subjects presented isolated teratozoospermia as the other semen parameters were normal. Besides, 20 healthy men with normal semen profiles and proven fertility were recruited as controls. All subjects in either group had no history of chemotherapy, radiotherapy, medication, varicocoele, or chronic illness. Sperm samples were collected into sterile pots by masturbation after 3 days of sexual abstinence. After sample liquefaction, standard semen parameters were evaluated according to the World Health Organization ${ }^{5}$ guidelines. Detailed morphological assessment was performed according to David et al, ${ }^{29}$ as modified by Auger \& Eustash ${ }^{7}$ and using $15 \%$ as reference value was performed to score the specific types of morphological abnormalities of spermatozoa. Each abnormal spermatozoon was evaluated for defects of the head, midpiece, and principal piece, and for the presence of excess residual cytoplasm (volume more than one-third of the sperm head size). Index of multiple morphological defects was calculated as multiple anomalies index (MAI), that is mean number of anomalies per abnormal spermatozoon. ${ }^{5}$ Spermatozoa viability was estimated by using eosin-nigrosin (Sigma, French) staining protocol, and it was expressed as a percentage of live spermatozoa. When the count of dead spermatozoa exceeds $42 \%$, a necrozoospermia is suspected. Each fresh semen sample was divided into two aliquots: one immediately served for Annexin and MitoPT assays and the other was washed twice in phosphate-buffered saline (PBS, pH 7.4), then centrifuged for $10 \mathrm{~min}$ at $3500 \mathrm{rpm}$ to obtain supernatant of seminal plasma and pellet of spermatozoa. Seminal plasma was frozen at $-20^{\circ} \mathrm{C}$ until oxidative stress analyses, and the pellet was then fixed in methanol/acetic acid (3:1) for at least $30 \mathrm{~min}$ at $4^{\circ} \mathrm{C}$. The fixed specimens were stored at $-20^{\circ} \mathrm{C}$ until 116 acridine orange assay.

\section{2 | Sperm phosphatidylserine (PS) externalization}

The translocation of PS to the outer leaflet of the plasma membrane was detected using the Annexin V Cy3.18 Apoptosis Detection Kit (Hexabiogen, biovision) according to the manufacturer's guidance. In the early apoptosis, PS, normally found on the cytoplasmic leaflet of the plasmatic membrane, translocates to the extracellular 
leaflet. Annexin V Cy3.18 (red fluorescence) joins to PS on the external surface of spermatozoa membrane undergoes cell death. A second stain, 6-carboxyfluorescein diacetate (6-CFDA, green fluorescence), is used to assess the viability and differentiate between apoptotic and necrotic cells. Using fluorescent microscopy, living cells stain only with 6-CFDA (Annexin V-negative, green). Necrotic cells stain only with Annexin $\vee$ Cy3.18 (negative, red). Early apoptotic cells stain with both Annexin V Cy3.18 (red) and 6-CFDA (Annexin V Cy3.18 positive/6-CFDA positive) and are therefore green-red cells. ${ }^{30}$ Aliquots of sperm suspension (3 million spermatozoa) were placed on poly-L-lysine-coated slides (Sigma), washed with binding buffer, and incubated with $50 \mu \mathrm{l}$ of double-label staining solution (Annexin V Cy3.18 and 6-CFDA) at room temperature protected from light. Analysis of the samples was realized using fluorescence microscopy (Leica DFC) as mentioned upon. At minimum, 100 spermatozoa were counted per slide through five random fields.

\subsection{Sperm mitochondrial function}

As described by the manufacturer, sperm mitochondrial function was analyzed on at least consecutive live spermatozoa with the commercial kit MitoPTJC-1 (immunochemistry technologies LLC). The Mito PT JC-1 assay detects the depolarization of the mitochondrial membrane applying the fluorescent dye JC-1. In health cells, JC-1 accumulates in negatively polarized mitochondria and emits an orange fluorescence at $590 \mathrm{~nm}$. When the potential of the mitochondrial membrane collapses in apoptotic or metabolically stressed cells, the JC-1 reagent is dispersed in the cell and emits green fluorescence at $527 \mathrm{~nm}$. Briefly, after washing with the $1 \mathrm{X}$ assay buffer (diluted 1:10 in distilled water), three millions of spermatozoa are stained with the MitoPT JC-1 and incubated for $30 \mathrm{~min}$. Then, a second washing is carried out in the $1 X$ assay buffer centrifuging at $2000 \mathrm{rpm} / 10 \mathrm{~min}$. Sperm scoring was done at $\times 40$ and $\times 100$ by using a fluorescence microscopy (Leica DFC.) Spermatozoa with green stained mitochondria were considered pathological.

\section{4 | Sperm DNA integrity}

Spermatozoa, obtained as described above, were thawed and centrifuged for $10 \mathrm{~min}$ at $1200 \mathrm{rpm}$, and the pellet was resuspended in TNE buffer $(50 \mathrm{~mm}$ Tris- $\mathrm{HCl}, \mathrm{pH} 7.4,100 \mathrm{~mm} \mathrm{NaCl}$, $0.1 \mathrm{~mm}$ EDTA) $(0.5 \mathrm{~mL})$ to $2 \times 10^{6}$ spermatozoa $/ \mathrm{ml}$ and held in ice until stain. The suspension $(200 \mu \mathrm{L})$ was subjected to brief acid denaturation by mixing with $400 \mu \mathrm{L}$ of chilled $\left(0^{\circ} \mathrm{C}\right)$ lysis solution [0.1\% Triton X-100 (v/v), 0.15 M NaCl,0.08 M HCl, pH 1.4], held for $30 \mathrm{~s}$, and mixed with $1.2 \mathrm{ml}$ acridine orange (Fluka AG, Switzerland) solution (50 $\mu \mathrm{g}$ acridine orange/ml in buffer: citric acid $0.1 \mathrm{M}, \mathrm{Na}_{2} \mathrm{HPO} 40.2 \mathrm{M}, \mathrm{NaCl} 0.15 \mathrm{M}$, EDTA $1 \mathrm{mM} \mathrm{pH}$ 6). Following a 3-min incubation, the samples were centrifuged at $1200 \mathrm{rpm}$ for $10 \mathrm{~min}$ and washed with TNE buffer $(100 \mu \mathrm{L})$; the pellet was spread on a slide, dried in an open area, and mounted using a mixture of glycerin and PBS [(v/v), $\mathrm{pH}$ 7.2]. All slides were prepared in duplicate and read on the same day with a fluorescence microscope (Leica, DFC). Sperm heads were subdivided into those showing a green and a red staining (orange-yellow staining was scored as the red one), as recommended. ${ }^{31} \mathrm{~A}$ total of 300 cells were assessed on each slide.

\section{5 | Measurement of seminal reduced glutathione (GSH)}

The seminal plasma content of reduced glutathione (GSH) was measured according to Srivastava \& Beutler ${ }^{32}$ method. Briefly, $0.2 \mathrm{~mL}$ of seminal plasma and $1.8 \mathrm{~mL}$ of distilled water were mixed with $3 \mathrm{~mL}$ of precipitating solution (Trichloroacetic acid 5\%). After standing for $5 \mathrm{~min}$, the solution was filtered and $1 \mathrm{~mL}$ of clear filtrate mixed with $4 \mathrm{~mL}$ of freshly prepared disodium hydrogenphosphate and $0.5 \mathrm{~mL}$ of DTNB reagent (5, 5'dithiobis-2-nitrobenzoic acid). Absorbance of the developed yellow color was read on a spectrophotometer at $412 \mathrm{~nm}$.

\section{6 | Measurement of seminal oxidized Glutathione (GSSG)}

The seminal plasma content of oxidized glutathione (GSSG) was measured according to the method of Akerboom \& Sies, ${ }^{33}$ in which $100 \mu \mathrm{L}$ of seminal plasma was mixed with $400 \mu \mathrm{L}$ of sodium carbonate and $4 \mu \mathrm{L}$ of pyridine. Then, the mixture was centrifuged at $3000 \mathrm{rpm} / 10 \mathrm{~min}$. The absorbance of the developed yellow color was read in a spectrophotometer at $412 \mathrm{~nm}$.

\section{7 | Measurement of seminal glutathione S-transferase activity (GST)}

The enzymatic activity of glutathione S-transferase (GST) in seminal plasma of all studied groups was determined according to the method used by Habig \& Jakoby. ${ }^{34}$ The activity of this enzyme was determined via the formation of 1-glutathione-2, 4-dinitrobenzene, which serves as a chromophore adsorbing at the wavelength of $340 \mathrm{~nm}$ (at $25^{\circ} \mathrm{C}$ ) from 1-Cl-2,4-dinitrobenzene (CDNB). GST activity was expressed in $\mu \mathrm{mol} / \mathrm{mg}$ of protein.

\section{8 | Measurement of seminal protein sulfhydryl groups (P-SH)}

The seminal plasma concentration of $\mathrm{P}-\mathrm{SH}$ in was measured as characterized by the modified method of Kasperczyk et $\mathrm{al}^{35}$ using DTNB, which undergoes reduction by compounds containing sulfhydryl groups, yielding the yellow anion derivative, 5-thio-2-nitrobenzoate, 
which absorbs at $412 \mathrm{~nm}$ as revealed using an automated Perkin Elmer analyzer. The results were shown in $\mu \mathrm{mol} / \mathrm{g}$ protein.

\section{9 | Measurement of seminal protein content}

The seminal plasma level of total proteins was determined spectrophotometrically using commercial reagent kits (Elecsys ${ }^{\circledR}$ S100B) from Roche Diagnostics Gmbh.

\subsection{0 | Statistical analysis}

The statistical analysis was done by using SPSS 21 (SPSS Inc). Studied parameters were given as mean \pm standard deviation or median (interquartile range). Student's $t$ test independent was used to estimate differences between the teratozoospermic and control groups. To test normal distribution, the Kolmogorov-Smirnov test was also used.
Correlation coefficients were calculated by Spearman's test. The criterion for difference was significant when $P<.05$ or highly significant when $P<.01$.

\section{3 | RESULTS}

\subsection{Analysis of semen and detailed morphology assessments}

The statistical analysis of semen parameters and the age of infertile group with isolated teratozoospermia and controls are given in Table 1. Among sperm shape anomalies, teratozoospermic showed higher percentages of sperm head abnormalities $(P=.002)$, tapered heads $(P=.018)$, double heads $(P=.01)$, and acrosome anomalies $(P=.001)$ with respect to control Table 1 . Regarding the abnormalities of tail, teratozoospermic men showed higher percentage of double tails $(P=.008)$ and coiled tails $(P=.046)$.

\begin{tabular}{|c|c|c|c|}
\hline & $\begin{array}{l}\text { Control group } n=20 \\
\text { Mean } \pm \text { SD }\end{array}$ & $\begin{array}{l}\text { Teratozoospermic group } \\
\mathrm{n}=69 \text { Mean } \pm S D\end{array}$ & $P$ value \\
\hline Age & $36.36 \pm 6.41$ & $36.3 \pm 7.16$ & .970 \\
\hline Volume & $3.14 \pm 1.6$ & $3.42 \pm 1.29$ & .608 \\
\hline $\mathrm{pH}$ & $7.97 \pm 0.14$ & $7.88 \pm 0.17$ & .510 \\
\hline Number $\left(10^{6} \mathrm{spz} / \mathrm{mL}\right)$ & $166.65 \pm 92.78$ & $134 \pm 127.94$ & .150 \\
\hline $\begin{array}{l}\text { Leukocyte concentration } \\
\left(10^{6} / \mathrm{mL}\right)\end{array}$ & $0.40 \pm 0.32$ & $0.55 \pm 0.86$ & .472 \\
\hline Total sperm motility (\%) & $50.26 \pm 6.56$ & $47.66 \pm 6.8$ & .150 \\
\hline Necrozoospermia & $15.89 \pm 8.33$ & $15.43 \pm 9.59$ & .851 \\
\hline Atypical forms (\%) & $82.45 \pm 3.13$ & $92.49 \pm 3.11$ & $.001^{\mathrm{b}}$ \\
\hline Head abnormalities (\%) & $15.2 \pm 1.7$ & $17.6 \pm 3.4$ & $.002^{b}$ \\
\hline Macrocephalic (\%) & $3.5 \pm 2.5$ & $2.65 \pm 2.6$ & .203 \\
\hline Microcephalic (\%) & $26.85 \pm 11.23$ & $31.10 \pm 14.92$ & .24 \\
\hline Tapered head (\%) & $10.25 \pm 7.06$ & $15.66 \pm 9.31$ & $.018^{a}$ \\
\hline Double head (\%) & $0.25 \pm 0.44$ & $1.34 \pm 1.85$ & $.01^{\mathrm{a}}$ \\
\hline Irregular head (\%) & $41.2 \pm 10.72$ & $40.31 \pm 13.39$ & .78 \\
\hline Thinned head (\%) & $8.1 \pm 4.43$ & $8.47 \pm 4.86$ & .75 \\
\hline Acrosomal anomalies & $14.85 \pm 4.93$ & $24.27 \pm 10.86$ & $.001^{b}$ \\
\hline Tail abnormalities (\%) & $4.52 \pm 2$ & $6.69 \pm 2.97$ & .003 \\
\hline Two tails (\%) & $0.55 \pm 0.75$ & $1.88 \pm 2.15$ & $.008^{b}$ \\
\hline Coiled tail (\%) & $10 \pm 6.6$ & $14.23 \pm 8.65$ & $.046^{\mathrm{a}}$ \\
\hline Bent tail (\%) & $6.55 \pm 4.29$ & $9.02 \pm 5.56$ & .07 \\
\hline Short tail (\%) & $1 \pm 1.1$ & $1.65 \pm 2.11$ & .189 \\
\hline Cytoplasmic droplet (\%) & $1.25 \pm 1.4$ & $1.5 \pm 1.96$ & .578 \\
\hline Multiple anomalies index & $1.52 \pm 0.15$ & $1.7 \pm 0.21$ & $.001^{b}$ \\
\hline
\end{tabular}

TABLE 1 Comparison of age, semen parameters, and detailed morphology characteristics between control and study groups

Note: Sperm parameters are expressed as mean \pm SD or median (interquartile range) depending on their normal distribution tested by the Kolmogorov-Smirnov test. Data were analyzed by independent $t$ test.

${ }^{a}$ Significant difference with control group $(P \leq .05)$.

${ }^{\mathrm{b}}$ Highly significant difference with control group $(P \leq .01)$. 
TABLE 2 Statistic comparison of apoptotic sperm markers and sperm DNA denaturation between control group and teratozoospermic group

\begin{tabular}{|lcccc} 
& Control $n=20$ & & \multicolumn{1}{c}{ Teratozoospermic $n=69$} & \\
\cline { 2 - 2 } & Mean \pm SD & & Mean \pm SD & P value \\
\hline AO staining assay & & & \\
\hline DNA denaturation (\%) & $11.38 \pm 5.47$ & $26.74 \pm 14.78$ & $.001^{\text {a }}$ \\
\hline MiTo PT assay & & & $.001^{\text {a }}$ \\
\hline MiTo PT (\%) & $26.4 \pm 19.55$ & $67.06 \pm 13.87$ & \\
\hline Annexin V-Cy3 assay & & & $.001^{\text {a }}$ \\
\hline Viable cells (\%) & $62.95 \pm 12.12$ & $36.23 \pm 15.15$ & $.001^{\text {a }}$ \\
\hline Apoptotic cells (\%) & $32.16 \pm 11.44$ & $59.58 \pm 15.15$ & .879 \\
\hline Necrotic cells (\%) & $3.66 \pm 4.22$ & $4.18 \pm 7.15$ & \\
\hline
\end{tabular}

Note: All values are expressed as mean \pm standard deviation and analyzed using the independent $\mathrm{t}$ test.

${ }^{a}$ Highly significant difference with control group $(P \leq .01)$; NS not significant Viable cells, ANX-/ CFDA+; apoptotic cells, ANX+/CFDA+; necrotic cells, ANX+/CFDA-

\subsection{Analysis of apoptotic sperm biomarkers}

The results of apoptotic sperm biomarkers analysis in the semen of men with isolated teratozoospermia and controls are presented in Table 2. As shown, semen of teratozoospermic showed high proportions of viable spermatozoa with externalized PS $(P<.01)$ and viable spermatozoa with decreased mitochondrial transmembrane potential when compared with controls $(P<.01)$. Moreover, viable spermatozoa without externalized PS were significantly less frequent in males with altered morphology than in those with normal one $(P<.01)$. Finally, the rate of necrotic spermatozoa did not differ significantly between infertiles and controls $(P>.05)$, in agreement with the percentage of necrozoospermia found by eosin staining Table 1.

\subsection{Analysis of sperm DNA denaturation}

The proportion of spermatozoa with denatured DNA was significantly higher in the teratozoospermic group than in control group $(P<.01)$, as assessed by acridine orange staining. Table 2 .

The detailed results of the correlation analyses between sperm morphology characteristics and both apoptotic biomarkers and DNA denaturation in ejaculated sperm samples of teratozoospermic men and fertile donors are shown in Table 3.

As presented, the proportions of viable spermatozoa presented statistically significant negative correlations with the percentage of atypical forms $(P<.01)$, and MAI $(P<.01)$, whereas apoptotic spermatozoa showed similar correlation, but positive. In particular, these correlations regarded head $(P<.001)$ and tails

TAB LE 3 Relationship between sperm morphology characteristics with apoptotic sperm biomarkers and sperm DNA denaturation. $\mathrm{N}=89$; control group $\mathrm{n}=20$; teratozoospermic group $\mathrm{n}=69$

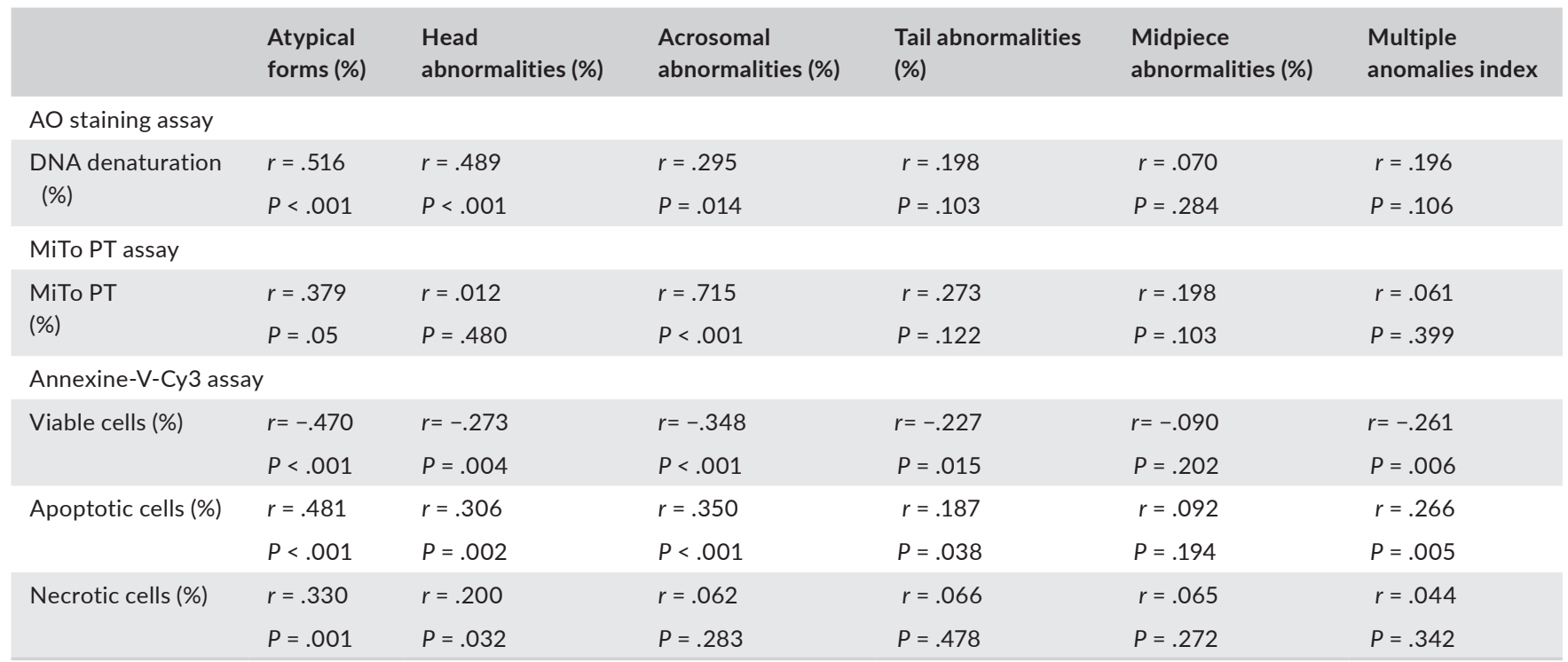

Note: Correlation analyses were performed using the Spearman rank-order correlation test. NS Not significant; viable cells, ANX-/CFDA+; apoptotic cells, ANX+/CFDA+ (\%), necrotic cells, ANX+/CFDA- 
abnormalities $(P<.05)$. Meanwhile, the proportions of dead spermatozoa with externalized PS showed significant correlation with the percentage of atypical forms $(P=.001)$ and head abnormalities $(P=.032)$.

In addition, the proportion of viable spermatozoa with decreased mitochondrial transmembrane potential was significantly and positively correlated with the percentage of atypical forms $(P<.01)$, and MAI $(P<.01)$. Finally, similar positive significant correlations with both percentages of atypical forms $(P<.01)$ and head abnormalities $(P<.01)$ were found also for the proportion of spermatozoa with denatured DNA Figure 1.

\subsection{Relationship between apoptotic sperm biomarkers and sperm DNA denaturation}

Negative correlations were noted between the proportion of viable spermatozoa without externalized PS (intact/normal spermatozoa) and both sperm DNA denaturation $(P=.018)$ and viable spermatozoa with decreased mitochondrial transmembrane potential denaturation $(P=.005)$ in sperm samples of teratozoospermic men and controls Figure 1 and Table 4. In contrast, positive correlations were found with the proportion of viable spermatozoa with externalized PS $(P=.050)$. The proportion of dead spermatozoa with externalized PS was correlated significantly and positively only with the high level of sperm DNA denaturation $(P=.040)$ Table 4 . On the other hand, we noted a positive but not significant correlation between the proportion of sperm DNA denaturation and the proportion of viable spermatozoa with decreased mitochondrial transmembrane potential $(P>$.05) Table 4.

\subsection{Analysis of seminal antioxidants and protein sulfhydryl concentration}

The seminal plasma antioxidant status of our samples is shown in Table 5. We detected a significant decrease in seminal GSH concentration in the group with teratozoospermia compared to controls $(P=.014)$. The seminal $\mathrm{P}$-SH concentration was also significantly decreased in the same group $(P=.024)$. However, this difference was not significant for the seminal GST activity $(P>.05)$. On the other hand, the seminal concentration of GSSG
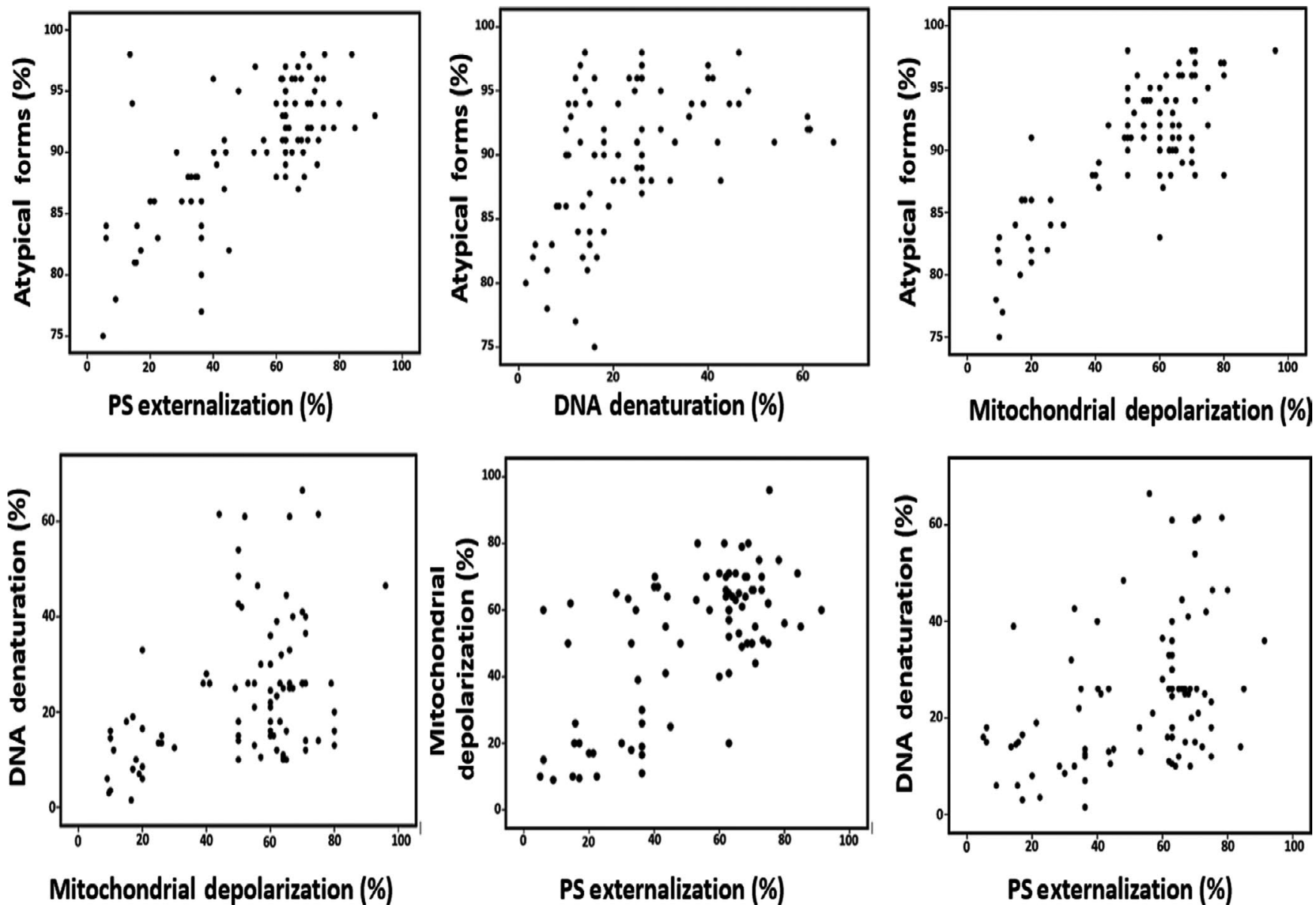

FIGURE 1 Relationships between atypical sperm form, sperm DNA denaturation, mitochondrial sperm depolarization, and apoptotic spermatozoa with phosphatidylserine externalization. Statistical analysis was performed using the Spearman rank-order correlation test 
TAB LE 4 Relationship between Apoptotic sperm biomarkers and sperm DNA denaturation. $\mathrm{N}=89$; control group $\mathrm{n}=20$; teratozoospermic group $\mathrm{n}=69$

\begin{tabular}{|lllll|}
\hline & DNA denaturation (\%) & MiTo PT (\%) & Viable cells (\%) & Apoptotic cells (\%) \\
\hline DNA denaturation (\%) & - & - & - \\
\hline MiTo PT (\%) & $r=.123$ & - & - \\
& $P=.325$ & - & - \\
\hline Viable cells (\%) & $R=-.248$ & $r=-.557$ & - & - \\
\hline Apoptotic cells (\%) & $P=.018$ & $P=.005$ & $r=-.930$ & - \\
& $r=.191$ & $r=.557$ & $P<.001$ & - \\
\hline Necrotic cells (\%) & $P=.05$ & $P=.005$ & $r=-.253$ & $r=.311$ \\
\hline
\end{tabular}

Note: Statistical analysis was performed using the Spearman rank-order correlation test. NS Not significant; viable cells, ANX-/CFDA+; apoptotic cells, ANX+/CFDA+; necrotic cells, ANX+/CFDA-

TABLE 5 Statistic comparison of oxidative biomarkers between control group and study group. $\mathrm{N}=89$; control group $\mathrm{n}=20$; teratozoospermic group $\mathrm{n}=69$

\begin{tabular}{|c|c|c|c|}
\hline & Control $n=20$ & $\begin{array}{l}\text { Teratozoospermic } \\
n=69\end{array}$ & \\
\hline & Mean \pm SD & Mean \pm SD & value \\
\hline $\mathrm{GST}(\mathrm{mmol} / \mathrm{min} / \mathrm{mg} \mathrm{P})$ & $0.1 \pm 0.16$ & $0.7 \pm 0.23$ & .43 \\
\hline GSH (mmol GSH/mg P) & $0.029 \pm 0.25$ & $0.0195 \pm 0.005$ & $.014^{\mathrm{a}}$ \\
\hline GSSG (mmol GSH/mg P) & $0.055 \pm 0.016$ & $0.077 \pm 2.047$ & $.021^{a}$ \\
\hline $\mathrm{P}-\mathrm{SH}(\mathrm{mg} / \mathrm{mL})$ & $0.89 \pm 1.13$ & $0.37 \pm 0.28$ & $.024^{a}$ \\
\hline
\end{tabular}

Note: All values are expressed as mean \pm standard deviation and analyzed using the independent $t$ test.

${ }^{a}$ Significant difference with control group ( $\left.P \leq .05\right)$; NS not significant.

was significantly increased in the group of the teratozoospermic $(P=.014)$

\subsection{Relationship between sperm morphology characteristics and seminal oxidative stress parameters}

Correlations between seminal antioxidant status, seminal P-SH level, and sperm morphology characteristics, as assessed in all recruited subjects, were also investigated in this study and presented in Table 6.

Significant correlations were found between the seminal level of GSH with the percentage of atypical forms $(r=-281, P=.009)$ and the total tail abnormalities $(r=-.205, P=.04)$. The seminal level of GSSG showed negative correlation only with the percentage of atypical forms $(P=.01)$.

Interestingly, the seminal level of $\mathrm{P}-\mathrm{SH}$ was negatively correlated with MAI ( $r=-.340, P=.017)$ and the total tail abnormalities $(r=$ $-.340, P=.017)$.

In contrast, none of the sperm morphology characteristics was correlated significantly to the seminal GST activity $(P>.05)$.

\section{7 | Relationship between seminal oxidative stress parameters with the apoptotic sperm biomarkers and sperm DNA denaturation}

The results in Table 6 illustrate the correlation between seminal oxidative stress parameters with the apoptotic sperm biomarkers and sperm DNA denaturation, as assessed in all the recruited subjects.

It can be noted that a significant positive correlation exists between the level of seminal GSH and the proportions of viable spermatozoa without externalized PS $(P=.05)$. In contrast, the proportions of viable spermatozoa with externalized PS were negatively and significantly correlated with the seminal level of GSH $(P=.02)$.

Furthermore, we noted another positive correlation between seminal P-SH concentration and the proportions of dead spermatozoa $(P=.03)$. Interestingly, a positive and significant correlation was observed between the seminal level of oxidized glutathione and the proportion of spermatozoa with denatured DNA $(P=.02)$.

\section{8 | Relationship between the oxidative parameters}

Correlation between the studied oxidative parameters was also investigated in teratozoospermic men and controls and reported in Table 7. Our study showed a negative correlation between GSH and GSSG contents $(P=.012)$ in seminal plasma of the studied groups. In contrast, a positive relationship was found between seminal GSH level and seminal P-SH $(P=.036)$.

\section{4 | DISCUSSION}

Sperm DNA integrity of men with teratozoospermia has recently been the subject of intense research studies which reported that these subjects show high levels of sperm nuclear defects. . $^{3,4,8,36}$ However, the origins of such defects are still a matter of debate. It 
TABLE 6 Relationship between sperm morphology characteristics and seminal oxidative stress biomarkers. $\mathrm{N}=89$; control group $n=20$; teratozoospermic group $n=69$

\begin{tabular}{|c|c|c|c|c|}
\hline & GSH & GSSG & GST & P-SH \\
\hline \multirow[t]{2}{*}{ Atypical forms (\%) } & $r=-.281$ & $r=.268$ & $r=-.027$ & $r=-.114$ \\
\hline & $P=.009$ & $P=.01$ & $P=.427$ & $P=.247$ \\
\hline \multirow{2}{*}{$\begin{array}{l}\text { Head } \\
\text { abnormalities (\%) }\end{array}$} & $r=-.118$ & $r=.165$ & $r=.036$ & $r=-.046$ \\
\hline & $P=.161$ & $P=.079$ & $P=.402$ & $P=.103$ \\
\hline \multirow{2}{*}{$\begin{array}{l}\text { Acrosomal } \\
\text { abnormalities (\%) }\end{array}$} & $r=-.222$ & $r=.208$ & $r=.058$ & $r=-.101$ \\
\hline & $P=.034$ & $P=.036$ & $P=.345$ & $P=.247$ \\
\hline \multirow{2}{*}{$\begin{array}{l}\text { Tail abnormalities } \\
\text { (\%) }\end{array}$} & $r=-.205$ & $r=.107$ & $r=.055$ & $r=-.350$ \\
\hline & $P=.04$ & $P=.180$ & $P=.355$ & $P=.016$ \\
\hline \multirow{2}{*}{$\begin{array}{l}\text { Midpiece } \\
\text { abnormalities (\%) }\end{array}$} & $r=-.003$ & $r=-.139$ & $r=.208$ & $r=.057$ \\
\hline & $P=.490$ & $P=.117$ & $P=.478$ & $P=.366$ \\
\hline \multirow{2}{*}{$\begin{array}{l}\text { Multiple anomalies } \\
\text { index }\end{array}$} & $r=-.149$ & $r=.088$ & $r=-.055$ & $r=-.354$ \\
\hline & $P=.113$ & $P=.227$ & $P=.355$ & $P=.015$ \\
\hline \multirow{2}{*}{$\begin{array}{l}\text { DNA denaturation } \\
\text { (\%) }\end{array}$} & $r=-.122$ & $r=.318$ & $r=.106$ & $r=-.020$ \\
\hline & $P=.193$ & $P=.02$ & $P=.266$ & $P=.459$ \\
\hline \multirow[t]{2}{*}{ MiTo PT (\%) } & $r=-.201$ & $r=.265$ & $r=-.364$ & $r=.247$ \\
\hline & $P=.246$ & $P=.152$ & $P=.168$ & $P=.261$ \\
\hline \multirow[t]{2}{*}{ Viable cells (\%) } & $r=.196$ & $r=-.146$ & $r=-.231$ & $r=.003$ \\
\hline & $P=.05$ & $P=.104$ & $P=.055$ & $P=.493$ \\
\hline \multirow[t]{2}{*}{ Apoptotic cells (\%) } & $r=-.246$ & $r=.070$ & $r=-.146$ & $r=-.003$ \\
\hline & $P=.02$ & $P=.273$ & $P=.156$ & $P=.493$ \\
\hline \multirow[t]{2}{*}{ Necrotic cells (\%) } & $r=-.128$ & $r=.081$ & $r=.223$ & $r=-.304$ \\
\hline & $P=.147$ & $P=.243$ & $P=.062$ & $P=.03$ \\
\hline
\end{tabular}

Note: Statistical analysis was performed using the Spearman rankorder correlation test. NS Not significant; viable cells, ANX-/CFDA+; apoptotic cells, ANX+/CFDA+; necrotic cells, ANX+/CFDA-

is known that both apoptosis and abnormal spermatogenesis and oxidative stress can cause sperm DNA damage. ${ }^{17,37-39}$ In this study, we aimed at assessing whether apoptosis and oxidative stress may be underlying mechanisms of DNA damage related to teratozoospermia. Thus, we determined the level of DNA breaks as well as the seminal antioxidant status and apoptotic features in sperm ejaculates from men with isolated teratozoospermia.

Regarding sperm DNA damage, we found an elevated percentage of spermatozoa with DNA denaturation in the group of infertile men compared to donors group. In addition, we identified significant relationships between the rate of DNA denaturation and abnormal sperm forms, especially those showing defects in head morphology, in agreement with previous studies. ${ }^{1,10,39-41}$ These findings are in agreement with Ammar et al ${ }^{3}$ and Ammar et al ${ }^{4}$ who used four assays to evaluate the nuclear sperm integrity of men with isolated teratozoospermia such as TUNEL, single-cell gel electrophoresis (comet assay), toluidine blue, and acridine orange and showed positive correlations between sperm DNA damage and different features of morphological abnormalities. Moreover, in vivo study of Cho et $\mathrm{al}^{42}$ demonstrated that mouse spermatozoa with reduced chromatin stability and protamine deficiency exhibit abnormal shape particularly
TABLE 7 Relationship between the different oxidative biomarkers. $\mathrm{N}=89$; control group $\mathrm{n}=20$; teratozoospermic group $\mathrm{n}=69$

\begin{tabular}{|c|c|c|c|c|}
\hline \multicolumn{5}{|c|}{ Oxidative biomarkers } \\
\hline & GSH & GSSG & GST & P-SH \\
\hline GSH & - & - & - & - \\
\hline \multirow[t]{2}{*}{ GSSG } & $r=-.285$ & & & \\
\hline & $P=.012$ & - & - & - \\
\hline \multirow[t]{2}{*}{ GST } & $r=-.172$ & $r=-.029$ & & \\
\hline & $P=.129$ & $P=.424$ & - & - \\
\hline \multirow[t]{2}{*}{ P-SH } & $r=.303$ & $r=.035$ & $r=-.148$ & \\
\hline & $P=.036$ & $P=.420$ & $P=.213$ & - \\
\hline
\end{tabular}

Note: Statistical analysis was performed using the Spearman rank-order correlation test; NS, not significant

abnormal head morphology, further strengthening the link between sperm DNA damage and abnormal morphology. In contrast, in the studies of Zini et $\mathrm{al}^{43}$, Chan et $\mathrm{al}^{44}$, Donnelly et $\mathrm{al},{ }^{45}$ no significant relationships were found between sperm DNA damage as well as atypical sperm forms and abnormal head morphology).

To detect apoptosis in ejaculated spermatozoa, we used Annexin $\mathrm{V}$-Cy3 in conjunction with a vital dye (CFDA), allowing to detect early and late apoptosis (or necrosis). ${ }^{12,46,47}$ The percentages of both necrotic and early apoptotic spermatozoa were significantly associated with the rate of atypical sperm forms and the rate of various forms of sperm abnormalities including head and tail. In opposite, the study by Shen et $\mathrm{al}^{48}$ presented only an association between altered seminal quality and a late stage of apoptosis and suggested that ejaculated spermatozoa contain only late apoptosis signs being the process began in testis. However, our data indicate that apoptosis can be triggered also during the transit in the male genital tract and thus signs of early stage of cell death in the ejaculated spermatozoa can be detected as well. Although recent studies support this hypothesis, ${ }^{28}$ additional studies are needed to validate this concept.

Another early feature of programmed cell death in ejaculated spermatozoa is mitochondrial depolarization. Mitochondrial disruption includes changes in the membrane potential and alterations to the oxidation-reduction potential of the mitochondria and was detected by membrane-permeant JC-1 dye which is widely used in apoptosis studies to monitor mitochondrial health.

We found that men with teratozoospermia showed a significantly higher proportion of viable spermatozoa with decreased mitochondrial transmembrane potential than controls in agreement with other studies. ${ }^{49-51}$ We observed also a significant positive correlation between translocation of PS and loss of mitochondrial membrane potential further evidencing that early stages of apoptosis phenomena might be indeed present in ejaculated spermatozoa with a high level of atypical sperm forms. However, further studies are needed to determine the mechanisms leading such plasma and mitochondria membrane alterations.

As mentioned, alterations of mitochondrial transmembrane membrane potential and PS externalization are early signs of 
apoptosis in somatic cells; these alterations precede other manifestations of programmed cell death, such as DNA fragmentation. ${ }^{46,49,52,53}$ Consistently, our study demonstrated that the DNA breaks is associated with the sperm translocation of PS and the loss of mitochondrial membrane potential.

As mentioned, another mechanism that could generate DNA damage in infertile men with teratozoospermia is oxidative attack. In this study, we evaluated important endogenous antioxidants in humans, which play a central role in the defense against oxidative attacks and toxins such as the GST enzyme and the level of free thiol. Regarding GST, we observed the presence of a detectable amount of GST in the seminal plasma of all studied subjects and no significant difference between the control and the teratozoospermic group. Data on GST in human seminal plasma are limited. ${ }^{54}$

The activity of GST is related to the two forms of GSH, the GSHr, and the GSSG one. However, there is little information on the effects of seminal glutathione on semen quality, and the results are controversial. Ochsendorf et al $^{54}$ found a reduction of GSH in men with oligozoospermia compared to fertile men, ${ }^{55,56}$ and other studies found GSH levels below the limit of detection $(<2.5 \mu \mathrm{M})$ in seminal plasma of the same type of subjects. In our study, the level of GSHr, albeit detectable in both group of subjects, was lower in teratozoospermic men compared to fertile men. In contrast, the seminal level of GSSG was significantly increased in the infertile group. These results were in line with those obtained by other reports ${ }^{57-59}$ but in contrast with reports which could not observe any difference in GSH concentration between fertile and infertile men. ${ }^{60}$

The impairment on seminal GSHr/GSSG levels in the infertile group may be due to an excessive ROS produced by the abnormal spermatozoa. Actually, we noted significant correlations between the percentage of atypical sperm form and the decreased and increased rates of seminal GSHr and GSSG, respectively. Raijmakers et $\mathrm{al}^{61}$ also noted that median rates of seminal GSH were significantly lower in infertile men as compared to controls and found positive relationships between seminal GSH level and sperm motility and morphology.

This result provides evidence that GSHr in seminal plasma seems to protect the quality of sperm cell against oxidative damage and to improve sperm morphology ${ }^{62}$ supporting the negative influence of low seminal glutathione level on semen quality. In fact, GSH can react directly with ROS by its free sulphydryl groups. During their presence in extracellular space, GSH is able to react directly with cytotoxic aldehydes generated during the lipo-peroxidation and thus protects the plasmatic membrane of spermatozoa. ${ }^{63}$ Accordingly, we can suggest that the sperm morphological defect in teratozoospermic samples can be linked to the over-oxidation of sperm protein.

This evidence is confirmed by the lower concentration of protein sulfhydryl groups (P-SH) in the seminal of men with a high level of atypical sperm forms observed in our investigation, in agreement with a previous study. ${ }^{64}$ The maintenance of $\mathrm{P}-\mathrm{SH}$ in semen is important for correct protein folding and activity, ${ }^{65,66}$ and sulfhydryl protein groups have been recently used as indirect biomarkers of oxidative stress. ${ }^{67,68}$ The positive and significant relationship found between GSHr and P-SH confirms that reduction in the seminal GSH level is associated with the decline of seminal antioxidant capacity and the increase of protein $\mathrm{SH}$ depletion leading to low sperm quality.

Impaired antioxidant status detected in the seminal plasma of men with isolated teratozoospermia may be an important risk factor for nuclear sperm defects. Indeed, we have clearly indicated that lower antioxidant status and decreased P-SH seminal concentrations were closely associated with an increase in the sperm DNA breaks. These correlations confirm also the essential role of seminal antioxidants in the protection of sperm DNA integrity against excessive ROS production. ${ }^{43,69-71}$ Overall, our finding is consistent with data from early reports demonstrated that teratozoospermic subjects have reduced antioxidant profile and increased DNA fragmentation in their semen ${ }^{4,11}$, because morphologically abnormal spermatozoa have a capacity to produce high levels of ROS causing DNA strand breaks. ${ }^{3,72}$ Free radicals can attack the nuclear material, engaging in $\mathrm{H}$-abstraction reactions with the ribose unit and inducing the formation of DNA base adducts. This process greatly destabilizes DNA integrity and may ultimately result in the formation of DNA strand breaks. The damage can be extended by the presence of poorly compacted sperm chromatin, possibly due to the impairment of the inter- and intra-protamine disulfide bonds.

Finally, the morphological as well as the biochemical and the nuclear alterations were accompanied by remarkable apoptotic signs. We also observed a statistically significant relationship between impaired seminal antioxidant capacity and the level of phosphatidylserine externalization in both live and dead spermatozoa. This finding is consistent with the idea that ROS are important factors triggering apoptosis. Indeed, it has been reported that ROS induce cytochrome c and caspases 9 and 3, ultimately resulting in a high frequency of single- and double-stranded DNA strand breaks. ${ }^{73,74}$ On the other hand, as discussed above, in teratozoospermic semen, ROS mediating such an attack could result from impaired antioxidant defenses and morphologically abnormal spermatozoa.

This study has some limitations. The link between the signs of DNA damage, apoptosis, oxidative stress, and morphological defects was investigated by detecting these variables in the bulk of semen samples and performing correlation analyses. Concomitant detection of DNA damage/apoptosis/oxidative stress in morphological abnormal spermatozoa, when feasible, would strengthen the results. Another issue is the use of acridine orange assay coupled to fluorescence microscopy which can be biased by a subjective score. However, results obtained here with this assay are consistent with other studies reporting higher rate of DNA breaks in men with teratozoospermia ${ }^{43,75-77}$ and using different techniques to assess sperm DNA fragmentation, like SCD and SCSA.

\section{5 | CONCLUSION}

Our study first investigated the association between early apoptosis markers, DNA breaks, and seminal oxidative status in sperm samples of men $\mathrm{s}$ with isolated teratozoospermia. Using correlation 
analyses, we showed that sperm DNA defects as well as apoptosis and seminal oxidative stress can be interlinked in the context of teratozoospermia and may constitute a unified pathogenic molecular mechanism. In fact, ROS generated from morphologically abnormal spermatozoa as well impaired seminal antioxidant defenses induces many changes in sperm cells, including membrane and DNA disorders and cell death; they can also act as an inducer of apoptosis in spermatozoa and in turn promote DNA damage.

Accordingly, combined analysis of oxidative stress, apoptotic markers, and nuclear defects provides complementary measurements for the evaluation of sperm quality and could contribute to provide adequate reproductive and genetic counseling for hypofertile men with isolated teratozoospermia.

\section{ACKNOWLEDGEMENTS}

We would like to thank all subjects, doctors, researchers, and laboratory team for their cooperation and support.

\section{CONFLICT OF INTEREST}

The authors declare that they have no conflicts of interest.

\section{COMPLIANCE WITH ETHICAL STANDARDS}

The protocol and Methods were approved by the local Institutional ethics committees 'the medical ethics and research committee of the Fattouma Bourguiba Monastir University Hospital'. All subjects had previously given informed consent for the study.

\section{ORCID}

Oumaima Ammar (iD https://orcid.org/0000-0001-7537-6465

\section{REFERENCES}

1. Brahem S, Mehdi M, Elghezal H, Saad A. Detection of DNA fragmentation and meiotic segregation in human with isolated teratozoospermia. J Assist Reprod Genet. 2011;28:41-48.

2. Mehdi $M$, Gmidène A, Brahem $S$, Guerin JF, Elghezal $H$, Saad A. Aneuploidy rate in spermatozoa of selected men with severe teratozoospermia. Andrologia. 2012;1:139-143.

3. Ammar O, Tesnim A, Zohra $\mathrm{H}$, et al. Investigation on the origin of sperm morphological defects: oxidative attacks, chromatin immaturity, and DNA fragmentation. Environ Sci Pollut Res. 2018;25:1-12.

4. Ammar O, Haouas Z, Hamouda B, et al. Relationship between sperm DNA damage with sperm parameters, oxidative markers in teratozoospermic men. Eur J Obstet Gynecol Reprod Biol. 2018;233:70-75.

5. WHO. World Health Organization Laboratory Manual for the Examination and Processing of Human. Semen. WHO Press; 2010.

6. Kruger TF, Menkveld R, Stander FSH, et al. Sperm morphologic features as a prognostic factor in in vitro fertilization. Fertil Steril. 1986;46:1118-1123.

7. Auger J, Eustash F. Standardisation de la classification morphologique des spermatozoïdes humains selon la méthode de David modifiée. Andrologie. 2000;10(4):358-373.

8. De Braekeleer M, Nguyen MH, Morel F, Perrin A. Genetic aspects of monomorphic teratozoospermia: a review. J Assist Reprod Genet. 2015;32:615-623.

9. Zidi-Jrah I, Hajlaoui A, Mougou-Zerelli S, et al. Relationship between sperm aneuploidy, sperm DNA integrity, chromatin packaging, traditional semen parameters, and recurrent pregnancy loss. Fertil Steril. 2016;105:58-64.
10. Ajina $T$, Ammar $O$, Haouas $Z$, et al. Assessment of human sperm DNA integrity using two cytochemical tests: Acridine orange test and toluidine blue assay. Andrologia. 2017;49(10):e12765.

11. Atig F, Kerkeni A, Saad A, Ajina M. Effects of reduced seminal enzymatic antioxidants on sperm DNA fragmentation and semen quality of Tunisian infertile men. J Assist Reprod Genet. 2017;34:373-381.

12. Hichri $\mathrm{R}$, Amor $\mathrm{H}$, Khammari $\mathrm{M}$, et al. Apoptotic sperm biomarkers and the correlation between conventional sperm parameters and clinical characteristics. Andrologia. 2018;50:1-9.

13. Hammadeh ME, Zavos PM, Rosenbaum P, Schmidt W. Comparison between the quality and function of sperm after semen processing with two different methods. Asian J Androl. 2001;3(2):125-130.

14. Mortimer D, Menkveld R. Sperm morphology assessment - historical perspectives and current opinions andrology lab corner. J Androl. 2001;22(2):192-205.

15. Lewis SE, John Aitken R, Conner SJ, et al. The impact of sperm DNA damage in assisted conception and beyond: Recent advances in diagnosis and treatment. Reprod Biomed Online. 2013;27(4):325-337.

16. Al-Dujaily SS, Al-Jnabi $\mathrm{MH}$, Jasim SN. The influence of Leukocytospermia and Teratozoospermia in IUI outcome. Int J Adv Res. 2015;3:255-265.

17. Sakkas D, Mariethoz E, Manicardi G, Bizzaro D, Bianchi PG, Bianchi $U$. Origin of DNA damage in ejaculated human spermatozoa. Rev Reprod. 1999;4(1):31-37.

18. Aitken RJ, De luliis GN. Origins and consequences of DNA damage in male germ cells. Reprod Biomed Online. 2007;14(6):727-733.

19. Aitken RJ, Bronson R, Smith TB, De luliis GN. The source and significance of DNA damage in human spermatozoa; a commentary on diagnostic strategies and straw man fallacies. Mol Hum. 2013;19(8):475-485.

20. Aitken RJ, West KM. Analysis of the relationship between reactive oxygen species production and leucocyte infiltration in fractions of human semen separated on Percoll gradients. Int J Androl. 1990;13(6):433-451.

21. Aitken RJ, Baker MA, Sawyer D. Oxidative stress in the male germ line and its role in the aetiology of male infertility and genetic disease. Reprod Biomed Online. 2003;7(1):65-70.

22. Said TM, Agarwal A, Sharma RK, Thomas AJ Jr, Sikka SC. Impact of sperm morphology on DNA damage caused by oxidative stress induced by $\beta$-nicotinamide adenine dinucleotide phosphate. Fertil Steril. 2005;83(1):95-103.

23. Said TM, Grunewald S, Paasch U, et al. Advantage of combining magnetic cell separation with sperm preparation techniques. Reprod Biomed Online. 2005;10(6):740-746.

24. Ammar O, Mehdi M, Tekeya O, Neffati F, Haouas Z. Novel association between apoptotic sperm biomarkers with seminal biochemical parameters and acetylcholinesterase activity in patients with teratozoospermia. J Assist Reprod Genet. 2019;36:2367-2378.

25. Aziz N, Said T, Paasch U, Agarwal A. The relationship between human sperm apoptosis, morphology and the sperm deformity index. Hum Reprod. 2007;22(5):1413-1419.

26. Marchiani S, Tamburrino L, Olivito B, et al. Characterization and sorting of flow cytometric populations in human semen. Andrology. 2014;2:394-401.

27. Paasch U, Agarwal A, Gupta AK, et al. Apoptosis signal transduction and the maturity status of human spermatozoa. Ann N Y Acad Sci. 2003;1010(1):486-488.

28. Brugnon F, Ouchchane L, Verheyen G, et al. Fluorescence microscopy and flow cytometry in measuring activated caspases in human spermatozoa. Int J Androl. 2009;32:265-273.

29. David G, Bisson JP, Czyglick F, Jouannet P, Gernigon C. Anomalies morphologiques du spermatozoïde humain. 1) Propositions pour un système de classification. J Gynecol Obstet Biol Reprod. 1975;1:17-36. 
30. Kemal Duru N, Morshedi M, Oehninger S. Effects of hydrogen peroxide on DNA and plasma membrane integrity of human spermatozoa. Fertil Steril. 2000;74(6):1200-1207.

31. Tejada RI, Mitchell JC, Norman A, Marik JJ, Friedman S. A test for the practical evaluation of male fertility by acridine orange (AO) fluorescence. Fertil Steril. 1984;42(1):87-91.

32. Srivastava SK, Beutler E. Accurate measurement of oxidized glutathione content of human, rabbit, and rat red blood cells and tissues. Anal Biochem. 1968;25(1):70-76.

33. Akerboom TPM, Sies H. Assay of glutathione, glutathione dissulfide, and glutathione mixed dissulfides in biological samples. Methods Enzymol. 1981;77:373.

34. Habig WH, Jakoby WB. Assays for Differentiation of Glutathione S-Transferases. Methods Enzymol. 1981;77:398-405.

35. Kasperczyk A, Dobrakowski M, Czuba ZP, Kapka-Skrzypczak L, Kasperczyk S. Environmental exposure to zinc and copper influences sperm quality in fertile males. Ann Agric Environ Med. 2016;23:138-143.

36. Braham A, Ghedir H, Zidi I, et al. Nuclear sperm quality in total polymorphic teratozoospermia and its impact on intracytoplasmic sperm injection outcome. Andrologia. 2019;51:1-10.

37. Marcon L, Boissonneault G. Transient DNA strand breaks during mouse and human spermiogenesis: new insights in stage specificity and link to chromatin remodeling. Biol Reprod. 2004;70(4):910-918.

38. Aitken RJ, Smith TB, Jobling MS, Baker MA, De luliis GN. Oxidative stress and male reproductive health. Asian J Androl. 2014;16:31-38.

39. Muratori M, Tamburrino L, Marchiani S, Kar S, Samanta L. Investigation on the origin of sperm DNA fragmentation: role of apoptosis, immaturity and oxidative stress. Mol Med. 2015;21:109-122.

40. Perrin A, Louanjli N, Ziane Y, et al. Study of aneuploidy and DNA fragmentation in gametes of patients with severe teratozoospermia. Reprod Biomed Online. 2011;22:148-154.

41. Skowronek F, Casanova G, Alciaturi J, et al. DNA sperm damage correlates with nuclear ultrastructural sperm defects interatozoospermic men. Andrologia. 2012;44(1):59-65.

42. Cho C, Willis WD, Goulding EH, et al. Haploinsufficiency of protamine-1 or -2 causes infertility in mice. Nat Genet. 2001;28:82-86.

43. Zini A, Phillips S, Courchesne A, et al. Sperm head morphology is related to high deoxyribonucleic acid stainability assessed by sperm chromatin structure assay. Fertil Steril. 2009;91:2495-2500.

44. Chan PJ, Corselli JU, Patton WC, \&, . A simple comet assay for archived sperm correlates DNA fragmentation to reduced hyperactivation and penetration of zona-free hamster oocytes. Fertil Steril. 2001;75:186-192.

45. Donnelly ET, McClure N, Lewis SE. Assessment ofDNA integrity and morphology of ejaculated spermatozoa from fertile and infertile men before and after cryopreservation. Hum Reprod. 2001;16:1191-1199.

46. Barroso G, Morshedi M, Oehninger S. Analysis of DNA fragmentation, plasma membrane translocation of phosphatidylserine and oxidative stress in human spermatozoa. Hum Reprod. 2000;15(6):1338-1344.

47. Oosterhuis GJE, Mulder AB, Kalsbeek-Batenburg E, Beschmann $\mathrm{H}$. Measuring apoptosis in human spermatozoa: A biological assay for semen quality? Fertil Steril. 2000;13(2):353-359.

48. Shen H-M, Dai J, Chia S-E, Lim A, Ong CN. Detection of apoptotic alterations in sperm in subfertile patients and their correlations with sperm quality. Hum Reprod. 2002;17(5):1266-1273.

49. Barroso G, Taylor S, Morshedi M, Manzur F, Gaviño F, Oehninger S. Mitochondrial membrane potential integrity and plasma membrane translocation of phosphatidylserine as early apoptotic markers: A comparison of two different sperm subpopulations. Fertil Steril. 2006;85(1):149-154.

50. Koppers AJ, De luliis GN, Finnie JM, McLaughlin EA, Aitken RJ. Significance of mitochondrial reactive oxygen species in the generation of oxidative stress in spermatozoa. J Clin Endocrinol Metab. 2008;93(8):3199-3207.

51. Zhang HB, Lu SM, Wang MCY, L, Li X \& Chen ZJ, . Early apoptotic changes in human spermatozoa and their relationships with conventional semen parameters and sperm DNA fragmentation. Asian J Androl. 2008;10(2):227-235.

52. Mignotte B, Vayssiere JL. Mitochondrial control of apoptosis. Adv Cell Aging Gerontol. 2001;5:93-122.

53. Suen DF, Norris KL, Youle RJ. Mitochondrial dynamics and apoptosis. Genes Dev. 2008;22(12):1577-1590.

54. Ochsendorf FR, Buhl R, Bästlein A, Beschmann H. Glutathione in spermatozoa and seminal plasma of infertile men. Hum Reprod. 1998;13:353-359.

55. Chaudhari AR, Piyali D, Ramji S. Study of oxidative stress and reduced glutathione levels in seminal plasma of human subjects with different fertility potential. Biomed Res. 2008;3:207-210.

56. Nabil H, Moemen LA, Abu Elela MH. Studying the levels of malondialdehyde and antioxidant parameters innormal and abnormal human seminal plasma. Aust J Basic Appl Sci. 2008;2(3):773-778.

57. Atig F, Raffa M, Ali HB, Abdelhamid K, Saad A, Ajina M. Altered antioxidant status and increased lipid per-oxidation in seminal plasma of Tunisian infertile men. Int J Biol Sci. 2011;8:139-149.

58. Atig F, Raffa M, Ali HB, Kerkeni A, Saad A, Ajina M. Impact of seminal trace element and glutathione levels on semen quality of Tunisian infertile men. BMC Urol. 2012;12:2-9.

59. Al-azzawie HF, Naeim M, Saleman ED. Evaluation of enzymatic and non- enzymatic antioxidant status in seminal plasma of Iraqi Infertile Men. Int J Adv Res. 2014;2:158-167.

60. Ebisch IM, Thomas CM, Peters WH, Braat DD, Steegers-Theunissen RP. The importance of folate, zinc and antioxidants in the pathogenesis and prevention of subfertility. Hum Reprod Update. 2007;13(2):163-174.

61. Raijmakers MTM, Roelofs HMJ, Steegers EAP, et al. Glutathione and glutathione S-transferases A1-1 and P1-1 in seminal plasma may play a role in protecting against oxidative damage to spermatozoa. Fertil Steril. 2003;79(1):169-172.

62. Lenzi A, Picardo M, Gandini L, et al. Glutathione treatment of dyspermia: Effect on the lipoperoxidation process. Hum Reprod. 1994;9(11):2044-2050.

63. Sorensen MB, Stoltenberg M, Danscher G, Ernst E. Chelation of intracellular zinc ions affects human sperm cell motility. Mol Hum Reprod. 1999;5(4):338-341.

64. Chen SS, Chang LS, Wei YH. Oxidative damage to proteins and decrease of antioxidant capacity in patients with varicocele. Free Radic Biol Med. 2001;30(11):1328-1334.

65. Smith CV, Jones DP, Guenthner TM, Lash LH, Lauterburg BH. Compartmentation of glutathione: Implications for the study of toxicity and disease. Toxicol Appl Pharmacol. 1996;140(1):1-12.

66. Mohanty G, Swain N, Goswami C. Histone retention, protein carbonylation, and lipid peroxidation in spermatozoa: Possible role in recurrent pregnancy loss. Syst Biol Reprod Med. 2016;62(3):201-212.

67. Kasperczyk A, Dobrakowski M, Czuba ZP, Horak S, Kasperczyk S. Environmental exposure to lead induces oxidative stress and modulates the function of the antioxidant defense system and the immune system in the semen of males with normal semen profile. Toxicol Appl Pharmacol. 2015;284(3):339-344.

68. Kasperczyk A, Dobrakowski M, Horak S, Zalejska-Fiolka \& J Birkner $E$. The influence of macro and trace elements on sperm quality. $J$ Trace Elem Med Biol. 2015;30:153-159.

69. Greco E, Romano S, lacobelli M, et al. ICSI in cases of sperm DNA damage: Beneficial effect of oral antioxidant treatment. Hum Reprod. 2005;20(9):2590-2594.

70. Showell M, Brown J, Yazdani A, Stankiewicz T, Hart J. Antioxidants for male subfertility (Review). Cochrane Libr. 2012. https://doi. org/10.1002/14651858.CD007411.pub3. 
71. Talevi R, Barbato V, Fiorentino I, I, Braun S, Longobardi S, Gualtier $\mathrm{R}$, . Protective effects of in vitro treatment with zinc, d-aspartate and coenzyme q10 on human sperm motility, lipid peroxidation and DNA fragmentation. Reprod Biol Endocrinol. 2013;11:81.

72. Ammar O, Houas Z, Mehdi M. The association between iron, calcium, and oxidative stress in seminal plasma and sperm. Environ Sci Pollut Res. 2019;26(14):14097-14105.

73. Said TM, Paasch U, Glander HJ, Agarwal A. Role of caspases in male infertility. Hum Reprod Update. 2004;10(1):39-51.

74. Agarwal A, Said TM. Oxidative stress, DNA damage and apoptosis in male infertility: A clinical approach. BJU Int. 2005;95:503-507.

75. Fadi B, Choucaira E, Rachkidia G, et al. High level of DNA fragmentation in sperm of Lebanese infertile men using Sperm Chromatin Dispersion test. Middle East Fertil Soc J. 2016;21:269-276.
76. Fatemeh D, Nasim T, Farzaneh F, Fatemeh Y, Ali Reza T. Evaluation of sperm protamine deficiency and apoptosis in infertile men with idiopathic teratozoospermia. Clin Exp Reprod Med. 2017;44:2.

77. Zini A, San Gabriel M, Baazeem A. Antioxidants and sperm DNA damage: A clinical perspective. J Assist Reprod Genet. 2009;26(8):427-432.

How to cite this article: Ammar O, Mehdi M, Muratori M. Teratozoospermia: Its association with sperm DNA defects, apoptotic alterations, and oxidative stress. Andrology. 2020;00:1-12. https://doi.org/10.1111/andr.12778 